\title{
Boutonneuse fever
}

\section{F A MORAGA, A MARTinez-ROIG, J L AlONSO, M BORONAT, AND F DOMINGo}

Social Security Children's Clinic, Residencia Sanitaria Francisco Franco, and Department of Paediatrics, Hospital Nuestra Señora del Mar, Barcelona, Spain

SUMMARY Sixty children, aged between 2 and 10 years, had boutonneuse fever during the summer months of 1979 and 1980. They presented with fever and a generalised maculopapular rash. The tàche noire could be seen at the site of the tick bite in $38(63 \%)$ of them. The antibody response, assayed nonspecifically, by the Weil-Felix reaction was positive in 52. A singe titre of more than 1:80 or a 4-fold increase between two paired specimens separated by a 7-day interval was considered diagnostic. Maximum titres were reached at the end of the second week of convalescence in $81 \%$ of patients. Treatment with oral oxytetracycline was effective in all cases.

Boutonneuse fever, a tick-borne rickettsial infection caused by Rickettsia conorii, is rare in childhood, even in endemic areas. ${ }^{12}$

Sixty children who had this disease in 1979 or 1980 form the basis of this report.

\section{Patients and methods}

Sixty children, aged between 2 and 10 years, with boutonneuse fever were diagnosed in the summer months of 1979 and 1980. All patients presented with fever and exanthema.

Clinical data of the patients are given in Table 1. Fever of $39-40^{\circ} \mathrm{C}$ was present in all and lasted for 6 to 14 days. A generalised, red, maculopapular rash erupted on the third day of fever (range, 1 to 7 days), and affected the palms of the hands and soles of the feet (Figs 1 and 2). The rash was petechial in 7 cases. The tàche noire at the site of the tick bite was noticed in $38(63 \%)$ cases; it consisted of a small ulcer with a black centre surrounded by a red halo (Fig. 3). The site of the

Table 1 Clinical symptoms in 60 patients with boutonneuse fever

\begin{tabular}{lll}
\hline Symptom & No of cases & $(\%)$ \\
\hline Fever & 60 & 100 \\
Exanthema & 60 & 100 \\
Tàche noire & 38 & 63 \\
Arthralgia/myalgia & 24 & 40 \\
Adenopathy & 20 & 33 \\
Hepatomegaly & 12 & 20 \\
Splenomegaly & 12 & 20 \\
Abdominal tenderness & 10 & 17 \\
Conjunctivitis & 8 & 13 \\
\hline
\end{tabular}

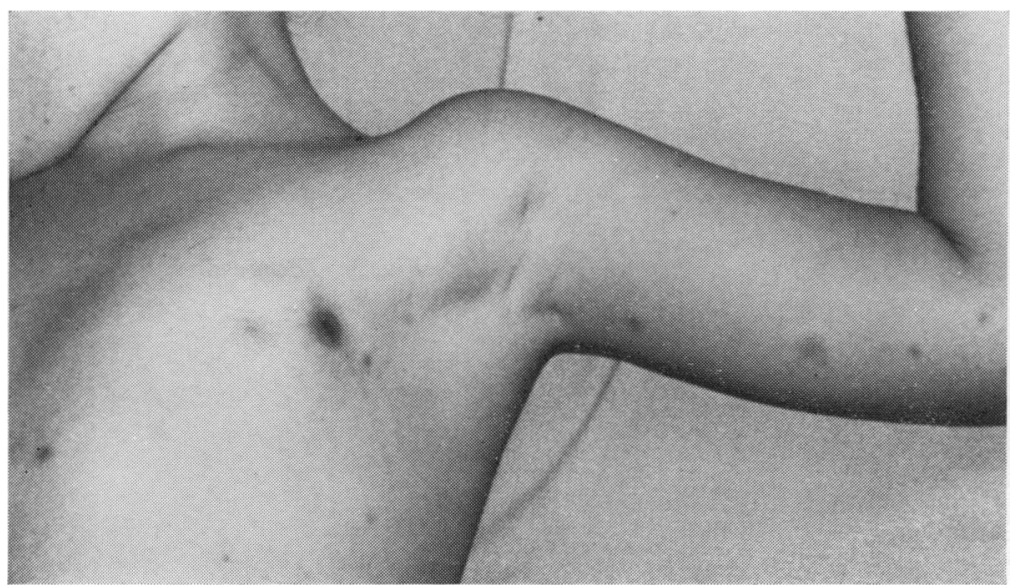

Fig. 1 Maculopapular rash with tàche noire lateral to the left nipple. 
primary lesion in 38 children is shown in Table 2. Enlarged lymph nodes were palpated in $33 \%$ of the patients. Five out of 10 patients with abdominal tenderness had vomiting and diarrhoea. Febrile convulsions occurred simultaneously with a rapid increase in temperature in one child.

The Weil-Felix reaction with OX-19, OX-2, and OX-K strains of Proteus vulgaris was positive in 52 patients. A single titre of more than 1:80 was considered diagnostic, or a 4-fold increase between two paired specimens separated by a 7-day interval.

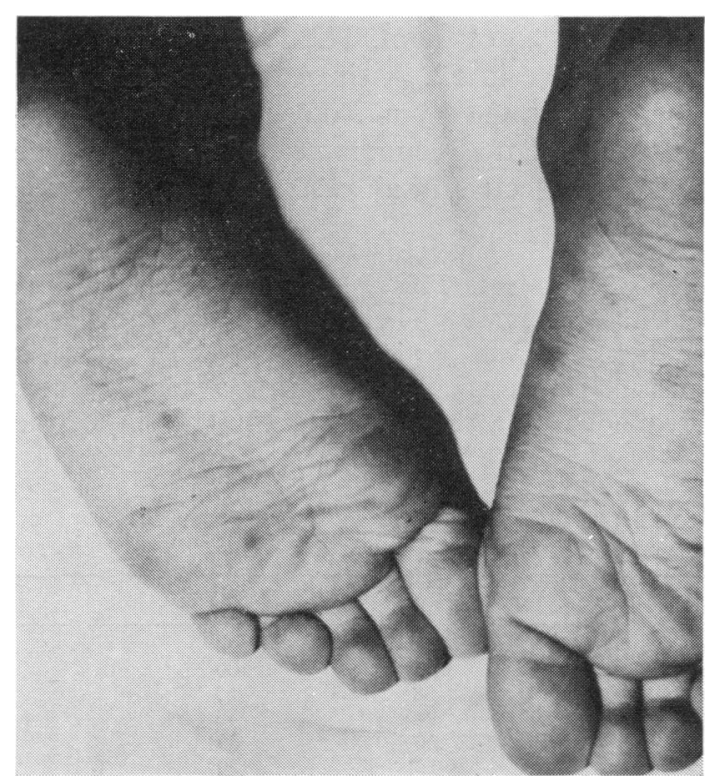

Fig. 2 Rash on the soles of the feet.
Table 2 Localisation of tàche noire in 38 cases

\begin{tabular}{ll}
\hline Site & No of cases \\
\hline Neck & 9 \\
Scalp & 7 \\
Back & 6 \\
Retroauricular area & 5 \\
Axillary region & 4 \\
Scrotum & 2 \\
Arm & 2 \\
Abdomen & 2 \\
Thorax & 1 \\
\hline
\end{tabular}

Titres ranged from $1: 40$ to $1: 640$; maximum titres were reached at the end of the first week of convalescence in 4 patients, at the end of the second week in 42 patients, and at the end of the third week in 6 patients. The remaining 8 patients with unconfirmed serological diagnoses were included in the study because of characteristic clinical featuresfever, tàche noire, and maculopapular eruption.

Treatment with oral oxytetracycline $(50 \mathrm{mg} / \mathrm{kg}$ per day for 7 days) was effective in all cases. Fever subsided after 2 days of treatment, and recovery was uneventful.

\section{Discussion}

Boutonneuse fever-also known as fièvre boutono neuse, Mediterranean fever, and Marseille fever-is prevalent in Mediterranean areas and is caused by $R$. conorii. The principal vector is Rhipicephalus sanguineus, a common tick parasite of dogs, rodents, and domestic animals, but other ticks may also transmit infection. These vectors constitute a reservoir of infection. Ticks inoculate rickettsiae directly at the time of the bite, and rickettsiae are introduced into the wound by scratching the

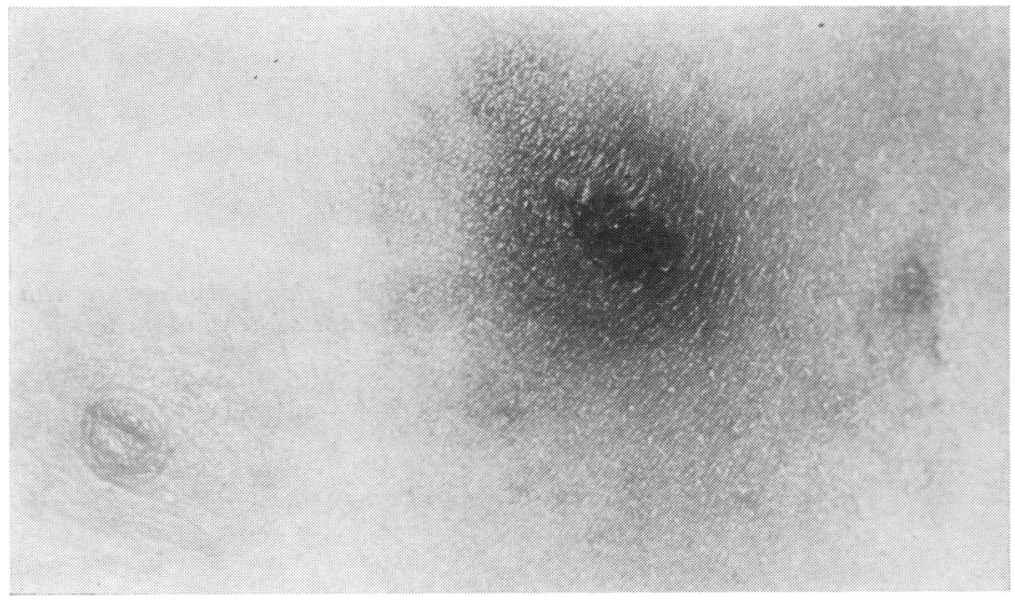

Fig. 3 Tàche noire lateral to the nipple. 
irritated site. Rarely, the disease may be acquired via the conjunctival route.

The tick-bite fevers of Africa, including Kenya fever or Kenya typhus and South African tick fever, together with Indian tick typhus, appear to be substantially the same disease as boutonneuse fever. In general, the epidemiology of these tick-borne rickettsioses includes ixodid ticks and small wild animals, which maintain rickettsias in nature; if humans are introduced accidentally into the cycle they become a deadend in the transmission chain. The dependence of boutonneuse fever on the tick for transmission results in a consistent seasonal peak beginning in late June and continuing until mid-October; $190 \%$ of our cases were seen in August and September. The role of the family dog may also be significant, especially for children since a child's canine pet may bring the ticks home. In our series a contact with dogs was confirmed in 49 cases.

Boutonneuse fever is milder than American spotted fever, and it is distinguished clinically by the small, local, indurated lesion with a necrotic centre which develops at the site of the tick bite (the eschar or tàche noire), and by regional adenopathy. Its rate of occurrence varies from 40 to $80 \%(63 \%$ in our experience), but its discovery is pathognomonic. Systemic illness starts about 5 to 7 days after the tick bite with the classical rickettsial symptoms of headache, fever, chills, malaise, and myalgia. The cause of the toxic and febrile state produced by rickettsial infection remains unknown; rickettsial toxins (lethal on mice) have been described, ${ }^{3}$ but their role in the pathogenesis of the disease is unknown.

Laboratory diagnosis is an indispensable adjunct to the identification of the disease of rickettsial aetiology, and involves serological identification of serum antibody. ${ }^{4}$ The antibody response may be assayed nonspecifically by the Weil-Felix reaction, and specifically using rickettsial antigen by complement fixation, rickettsial agglutination, and neutralisation of toxic activity. ${ }^{5}$ The Weil-Felix reaction relies on the antigen cross-reactivity between certain Proteus sp. bacteria and the antigens of the Rocky Mountain spotted fever and other rickettsiae (including $R$. conorii). Three Proteus sp. strains are generally used-namely, OX-19, OX-2, and OX-K; the test is an agglutination reaction. Single titres of $1: 80$ or $1: 160$, and rising titres to a 4-fold increase between two paired specimens strongly support the diagnosis. WeilFelix antibodies begin to appear at about the seventh day and peak about the third week; $81 \%$ of our positive reactions were found at the end of the second week. Normal serum from persons living in endemic localities often show an agglutination titre of 1:50. The Weil-Felix reaction shows an anamnestic response in a number of febrile diseases, especially typhoid fever and relapsing fevers. ${ }^{6}$

Because a rising titre may be of diagnostic value, a serum specimen should be tested for Weil-Felix antibody as soon as the possibility of boutonneuse fever is considered. An early negative titre may provide a useful baseline for later comparison. Thirty-two out of our 52 patients agglutinated both OX-19 and OX-2 strains, while the remaining 20 agglutinated single strains (OX-19 or OX-2). In 9 patients low titres $(1: 40)$ were given with OX-K strains; they were interpreted as cross-reactions, as positive titres are diagnostic for tsutsugamushi disease. ${ }^{6}$ Purified $R$. conorii antigens for specific tests were not available in our laboratory. Edlinger ${ }^{5}$ reported good agreement between complement fixation and indirect microimmunofluorescence when compared for specificity and sensitivity in detection of antibodies against $R$. conorii in acute and convalescent human sera.

Tetracyclines are effective therapeutic agents for boutonneuse fever; our patients became afebrile after 2 or 3 days of treatment and recovery was rapid without sequelae. A case fatality rate of $1-2 \%$ has been reported in adults, ${ }^{6}$ often in severe forms with hepatic involvement, ${ }^{7}$ myocarditis, or neurological damage. Children generally recover.

\section{References}

1 Carmina M, Puma G, Pitruzzella E. Rilievi sulla febbre bottonosa del Mediterraneo. Minn Med 1977; 68: 2357-60.

2 Bourgeade A, Jean Pastor M J, Raoult D. Notes sur la fièvre boutonneuse Méditerranienne (apropos de 40 cas récents á Marseilles). Bull Soc Pathol Exot 1979; 72: 308-14.

3 Schaffner W. The rickettsioses. In: Fitzpatrick T B, Eisen A Z, Wolff K, Freedberg I M, Austen K F, eds. Dermatology in general medicine, second edition. New York: McGraw-Hill, 1979: 1563-70.

4 Eickhoff T C. Rickettsial infections. In: Practice of medicine, sixth edition. Vol. 3, chapter 44. New York: Harper \& Row, 1978: 17-8.

5 Edlinger E. Serological diagnosis of Mediterranean spotted fever. Ann Microbiol (Paris) 1979; 130: 203-11.

- Freeman B A, ed. The rickettsiae. In: Burrows textbook of microbiology, twenty-first edition. Philadelphia: Saunders 1979: 889.

7 García San Miguel J, Soriano E, Bruguera M, Martínez Vea A, Vivancos J, Urbano Márquez A. La afección hepática en la fiebre botonosa. Med Clin (Barc) 1979; 72: 175-8.

Correspondence to $\mathrm{Dr}$ Fernando A Moraga, Clinica Infantil de la Seguridad Social, Paseo Valle Hebrón s/n, Barcelona, Spain.

Received 6 April 1981 